
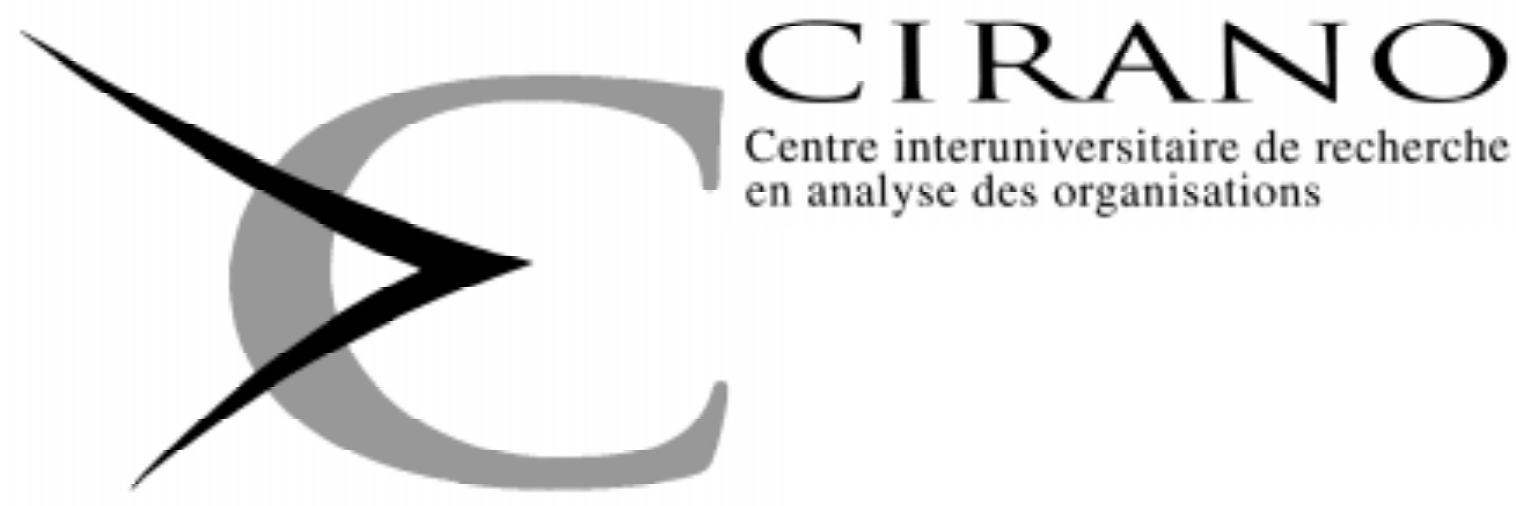

Centre interuniversitaire de recherche en analyse des organisations

Série Scientifique

Scientific Series

$N^{0} 95 s-5$

AN ANALYSIS OF THE REAL

INTEREST RATE UNDER

REGIME SHIFTS

René Garcia, Pierre Perron 


\section{CIRANO}

Le CIRANO est une corporation privée à but non lucratif constituée en vertu de la Loi des compagnies du Québec. Le financement de son infrastructure et de ses activités de recherche provient des cotisations de ses organisations-membres, d'une subvention d'infrastructure du ministère de l'Industrie, du Commerce, de la Science et de la Technologie, de même que des subventions et mandats obtenus par ses équipes de recherche. La Série Scientifique est la réalisation d'une des missions que s'est données le CIRANO, soit de développer l'analyse scientifique des organisations et des comportements stratégiques.

CIRANO is a private non-profit organization incorporated under the Québec Companies Act. Its infrastructure and research activities are funded through fees paid by member organizations, an infrastructure grant from the Ministère de l'Industrie, du Commerce, de la Science et de la Technologie, and grants and research mandates obtained by its research teams. The Scientific Series fulfils one of the missions of CIRANO: to develop the scientific analysis of organizations and strategic behaviour.

\section{Les organisations-partenaires / The Partner Organizations}

-Ministère de l'Industrie, du Commerce, de la Science et de la Technologie.

-École des Hautes Études Commerciales.

-École Polytechnique.

- Université de Montréal.

-Université Laval.

-McGill University.

-Université du Québec à Montréal.

-Bell Québec.

-La Caisse de dépôt et de placement du Québec.

-Hydro-Québec.

-Banque Laurentienne du Canada.

-Fédération des caisses populaires de Montréal et de l'Ouest-du-Québec.

-Téléglobe Canada.

Ce document est publié dans lintention de rendre accessible les résultats préliminaires de la recherche effectuée au CIRANO, afin de susciter des échanges et des suggestions. Les idées et les opinions émises sont sous l'unique responsabilité des auteurs, et ne représentent pas nécessairement les positions du CIRANO ou de ses partenaires.

This paper presents preliminary research carried out at CIRANO and aims to encourage discussion and comment. The observations and viewpoints expressed are the sole responsibility of the authors. They do not necessarily represent positions of CIRANO or its partners.

ISSN 1198-8177 


\title{
An Analysis of the Real Interest Rate Under Regime Shifts
}

\author{
René Garcia ${ }^{\dagger}$, Pierre Perron
}

\begin{abstract}
Résumé
This study considers the time series behavior of the U.S. real interest rate from 1961 to 1986. We provide a statistical characterization of the series using the methodology of Hamilton (1989), by allowing three possible regimes affecting both the mean and variance of the series. The results suggest that the ex-post real interest rate is essentially random around a mean that is different for the periods 1961-1973,1973-1980 and 1980-1986. The variance of the process is also different in these episodes being higher in both the 1973-1980 and 1980-1986 sub-periods. The inflation rate series is also analyzed using a three regime framework and again our results show interesting patterns with shifts in both mean and variance. Various model selection tests are run and both an ex-ante real interest rate and an expected inflation series are constructed. Finally, we make clear how our results can explain some recent findings in the literature.

Cette étude sintéresse au comportement des séries du taux d'intérêt réel américain de 1961 à 1986. En utilisant la méthodologie d'Hamilton (1989), la modélisation statistique des séries se fait en postulant trois régimes possibles affectant la moyenne et la variance de celles-ci. Les résultats suggèrent que le taux d'intérêt réel ex-post est essentiellement un processus non corrélé et centré sur une moyenne qui diffère sur les périodes 1961-1973, 1973-1980 et 1980-1986. La variance du processus est aussi différente pour chacune de ces périodes, étant plus élevée dans les sous périodes 1973-1980 et 1980-1986. Les séries du taux d'inflation sont aussi analysées à la lumière de ce modèle à trois régimes et les résultats traduisent encore un comportement intéressant de celles-ci, avec des changements dans la moyenne et la variance. Différents tests de spécification sont utilisés et des séries, à la fois du taux d'intérêt réel ex-ante et de linflation anticipée, sont construites. Enfin, Il est montré comment ces résultats peuvent expliquer certaines conclusion récentes de la littérature
\end{abstract}

Key Words: Nonstationary series, inflation rate, unit root, structural change.

Mots-clés : séries non-stationnaires, taux d'inflation, racine unitaire, changement structurel.

JEL Classification: C22, E43.

\begin{abstract}
We wish to thank James Hamilton for making available his computer program for the estimation of the two-state model, and Frederic Mishkin for useful comments and for providing some of the data used in this study. We would also like to thank a referee and the editor (James Stock) for useful comments. Financial support is acknowledged from the Social Sciences and Humanities Research Council of Canada, the Natural Sciences and Engineering Council of Canada, the Fonds pour la Formation de Chercheurs et l'Aide à la Recherche du Québec and the John M. Olin Program for the Study of Economic Organization and Public Policy at Princeton University.

Address for correspondence: Pierre Perron, C.R.D.E, Université de Montréal, C.P. 6128, Succ. A, Montréal, Québec, Canada, H3C 3J7
\end{abstract}

${ }^{\dagger}$ Département de sciences économiques et C.R.D.E., Université de Montréal, et CIRANO.

‡ Département de science économiques et C.R.D.E., Université de Montréal. 
Is the ex-ante real interest rate constant? The consensus among economists is that it is not, although they do not agree on the source of its fluctuations: some favor monetary policy, others fiscal policy. Empirically, in the United States, the hypothesis of a constant ex-ante real interest rate is generally rejected for most periods, except perhaps the 1953-71 period chosen by Fama (1975) to test the efficiency of the Treasury Bill market ${ }^{1}$. Recently, Rose (1988) asked another question: Is the ex-ante real interest rate stable or is it characterized by a univariate process with a unit root? For many periods and countries, he failed to reject ${ }^{2}$ the presence of an integrated component in the ex-post real interest rate, as did Walsh (1987) for various sample periods in the United States.

Potential nonstationarities of the ex-ante real interest rate have important implications not only for determining the effects of monetary policy or fiscal policy, but also for some issues that are central to financial theory. The widely used BlackScholes' formula for pricing options is based on an assumption of a constant ex-ante real interest rate. Also, as argued by Rose (1988), the nonstationarity of the real interest rate could lead to the rejection of some equilibrium asset pricing models such as the consumption CAPM. Therefore, it seems important to assess if the ex-ante real interest rate is constant, at least over some long enough periods, or if it exhibits a nonstationary behavior.

To conduct this assessment, our empirical analysis uses the ex-post real interest rate, that is the difference between the nominal interest rate $\left(i_{t}\right)$ and the inflation rate $\left(\pi_{t}\right), r_{t}=i_{t}-\pi_{t}$. Except for independent forecast errors, this is equivalent, under the assumption that agents use available information efficiently, to analyzing the ex-ante real interest rate, defined as $i_{t}-\pi_{t}^{\mathrm{e}}$ where $\pi_{t}^{\mathrm{e}}$ is the market's expectation of inflation. Our goal is to provide a statistical description of the time path of the ex-post real interest rate that allows nonstationarity in the form of infrequent changes in mean and variance. As noted by Perron (1990), such structural changes can be important factors in characterizing the ex-post real interest rate. To allow for an arbitrary number of changes occurring at unknown times, we use the Markov

\footnotetext{
${ }^{1}$ Mishkin's (1981) thorough study rejects strongly the hypothesis of a constant real interest rate for both the 1953-1979 and 1931-1952 periods, attributing Fama's results to the insufficient variation in the real interest rate over the period 1953-1971, as noted previously by Shiller (1980). For the debate over the constancy of the real interest rate, see Nelson and Schwert (1977), Garbade and Wachtel (1988), and Fama and Gibbons (1982).

${ }^{2}$ The results of Rose (1988) have recently been criticized by Gokey (1990). He argues that Rose used incorrect inferential procedures. With the correct procedures, he shows that both the nominal interest rate and the inflation rate are integrated of order one. Such a result does not imply anything about the time series behavior of the real interest rate, which would depend on whether or not the inflation rate and the nominal rate are cointegrated. As argued below, there appears to be no such cointegration (with a unit cointegrating vector) since one cannot reject, using standard test procedures, that the ex-post real interest rate is integrated.
} 
switching model proposed by Hamilton (1989). For the time span covered by our study, 1961-1986, we show, with two different data sets, that such a statistical description is appropriate when three states are allowed. The first data set consists of quarterly series (1961:1-1986:3) at annual rates drawn from the Citibase data bank. It uses the U.S. 90-day Treasury bill rate for the nominal interest rate and a quarterly inflation rate series constructed from the U.S. CPI non-seasonally adjusted ${ }^{3}$. We will also use for comparative purposes a monthly data set used in Mishkin (1990) that covers the period 1961:1-1986:12. The major difference is that the inflation rate series is calculated from a CPI series with proper adjustments for treating housing costs on a rental-equivalence basis throughout the sample ${ }^{4}$. We concentrate on the quarterly version of this data set obtained by extracting the end-of-quarter figures from the monthly series. Figures 1.a and 1.b contain a graph of the various series considered. Since the nominal interest rate series is basically the same in both data sets, the difference in the inflation rate series will be directly reflected in the ex-post real interest rate series.

Our results support Fama's original characterization of the ex-ante real interest rate as essentially constant with, however, the crucial difference that the mean of the series is subject to occasional shifts. The endogenously determined shifts in the level of the series occur at the beginning of 1973 and in the middle of 1981. This characterization of the ex-ante real interest rate contrasts with Huizinga and Mishkin's (1986) study which identifies October 1979 and October 1982 as shifts in the ex-ante real interest rate to argue that monetary policy has important effects on this variable, since these dates correspond to the well-documented changes in the Federal Reserve's operating procedures. The dates of our shifts are more in line with the sudden jump in oil prices in 1973 and with the rise of the federal budget deficit in the later part of 1981 and the beginning of 1982 . Moreover, we argue that it is precisely because of these shifts that the unit root hypothesis could not be rejected in the various tests performed by Walsh (1987) and Rose (1988).

The three-state specification selected for the ex-post real interest series is obtained after a thorough testing procedure. The identification of the number of regimes in Markov switching models cannot be done through the usual likelihood ratio, Lagrange multiplier, or Wald tests since their asymptotic distribution is nonstandard. Although some partial results are available (Hansen (1992), Garcia (1992)), no general solution exists to this testing problem. We therefore use a battery of tests

\footnotetext{
${ }^{3}$ We also estimated the various models presented below with seasonally adjusted data. The results were qualitatively similar and the conclusions unchanged.

${ }^{4}$ This adjustment for the inflation series was first used in a study by Huizinga and Mishkin (1984). The nominal interest rate is the three-month Treasury bill rate obtained from the Center for Research in Security Prices (CRSP) at the University of Chicago.
} 
that address the problem in various ways. All tests concur in selecting the three-state specification.

Although the endogenously dated shifts can be given an economic interpretation by associating them with coinciding economic events, our statistical characterization of the ex-post real interest rate series should not be interpreted as a structural model whereby policy makers could manipulate real interest rates over long periods. It could be viewed however as a reduced form equation coming from the firstorder condition of an equilibrium asset pricing model. For example, Bonomo and Garcia (1991) propose an exchange economy asset pricing model in which the exogenously determined endowment process represented by real consumption growth follows a three state Markov switching model. In such a model, the equilibrium real interest rate is also characterized by a three state process. Shocks to the real consumption growth rate coming from either the monetary side, through inflation, or the fiscal side, through nominal consumption, are therefore transmitted to the real interest rate, and it is such stylized features that our characterization is trying to capture.

Since our results imply a Markov switching model with transition probabilities near the boundaries, with each state occurring only once in all series analyzed, they should not be viewed, from a statistical perspective, as providing a model of the ex-post real rate that would be particularly appropriate for medium and long term forecasting. They indicate the presence of three segments with different means, but the possible appearance of a fourth or fifth "regime" in the future cannot be ruled out. The results provide, however, an ex-post characterization of the statistical properties of the real rate that could be useful in directing attention to specific classes of models for future research, such as models involving a noise component with mean and variance shifting at random times and with a random magnitude of change. In brief, our results allow us to state a series of facts about the number of segments present in the horizon covered, the magnitude of the mean and variance in each segment, the nature of the dynamics in the noise component, and the timing of the changes in regime, all facts that are helpful in interpreting several results already available in the literature.

Since the ex-post real interest rate is the difference between the nominal interest rate and the inflation rate, it is informative to identify where the shifts occurred in these series using the same Markov switching models. Since Hamilton (1988) used a two-state Markov model to characterize the nominal interest rate, we will limit ourselves to modeling the inflation rate. Our three-state Markov switching model for

\footnotetext{
${ }^{5}$ Hamilton (1988) identifies a persistent change in regime in the nominal interest rate between October 1979 and October 1982, a period which corresponds to the changes in the Federal Reserve's operating procedures. We did verify that the results obtained with our data sets are very close to Hamilton's results. We also estimated a three-regime model for the nominal interest rate series. The results (not reported) show an important jump in the mean and variance of the series from 1979:4 until 1982:4.
} 
the inflation rate over the period 1961-1986 points to some important regime shifts in the mean and the variance of the series. Our results show that during the 1973-1980 period both the mean and the variability of the inflation rate were high, supporting Okun's (1971) and Friedman's (1977) views. Therefore, our results seem to stand in contrast with Engle's (1983) rejection of a link between the mean and the variance of inflation using an ARCH methodology.

The paper proceeds as follows. Section I presents the statistical methodology used to characterize the ex-post real interest rate and the inflation rate, as well as the estimation method. Section II discusses the estimation results for the two models, emphasizing their implications in terms of unit root issues and monetary versus fiscal policy effects for the ex-post real interest rate, and of the mean-variability debate for the inflation rate. Section III derives the associated ex-ante real interest rate and the expected inflation series. Within sample forecasts are also compared to the forecasts obtained from a random walk model and a fourth-order autoregressive model for the ex-post real interest rate and the inflation rate. In Section IV, various tests and sensitivity analyses are conducted to justify the number of regimes specified and to explore the general robustness of the results. Section V concludes. Additional technical material on the testing procedures is provided in an Appendix.

\section{The Model and the Estimation Method}

To describe both the ex-post real interest rate and the inflation rate, we use the following autoregressive specification of order 2 :

$$
\left(\mathrm{S}_{\mathrm{t}}\right)=\phi_{1}\left[\mathrm{y}_{\mathrm{t} \& 1}-\mu\left(\mathrm{S}_{\mathrm{t} \& 1}\right)\right]+\phi_{2}\left[\mathrm{y}_{+\& 2}-\mu\left(\mathrm{S}_{\mathrm{t} \& 2}\right)\right]+\sigma(
$$

where the mean $\mu$ and the standard deviation $\sigma$ of the process depend on the regime at time $t$, indexed by $S_{t}$, a discrete valued variable, and $\{\epsilon\}$ is a sequence of i.i.d. $\mathrm{N}(0,1)$ random variables. Given that Perron $(1990)$ rejects the unit root hypothesis for the Citibase quarterly ex-post real interest rate allowing for one change in regime in 1980:3, we specify that the roots of $\left(1-\phi_{1} z-\phi_{2} z^{2}\right)=0$ are outside the unit circle. A similar result holds for the Mishkin quarterly real interest rate series 6 .

To make model (1) tractable, the econometrician must specify a stochastic process for the variable $S_{t}$ Hamilton $(1988,1989,1990)$ proposes to model $S_{t}$ as the outcome of an unobserved discrete-time, discrete-state Markov process, building on

\footnotetext{
${ }^{6}$ Using the procedure described in Perron (1990) with a break in 1980:3, the t-statistic for a unit root is $-7.31(k=0)$ allowing a rejection at less than the one percent level, with $k$ denoting the number of first differences added in the regression. Note that to perform these tests, not all breaks need to be taken into account. Taking into consideration the largest one may be sufficient.
} 
an original idea by Goldfeld and Quandt (1973). With a three-state, first-order Markov process, where $S_{t}$ can take the values 0,1 or 2 , we can write the transition probability matrix as:

$$
\mathrm{P}=\left[\begin{array}{lll}
\mathrm{p}_{\infty} & \mathrm{p}_{01} & \mathrm{p}_{02} \\
\mathrm{p}_{10} & \mathrm{p}_{11} & \mathrm{p}_{12} \\
\mathrm{p}_{20} & \mathrm{p}_{21} & \mathrm{p}_{22}
\end{array}\right],
$$

where:

$$
p_{i j}=\operatorname{Pr}\left[S_{t}=j \mid S_{t \& d}=i\right] \text { with } \sum_{j^{\prime} 0}^{2} p_{i j}=1 \text { for all i. . }
$$

The state-dependent means and variances are specified linearly as:

$$
\begin{aligned}
& \mu\left(\mathrm{S}_{\mathrm{t}}\right)=\alpha_{0}+\alpha_{1} \mathrm{~S}_{1 \mathrm{t}}+\alpha_{2} \mathrm{~S}_{2 \mathrm{t}}, \\
& \sigma\left(\mathrm{S}_{\mathrm{t}}\right)=\omega_{0}+\omega_{1} \mathrm{~S}_{1 \mathrm{t}}+\omega_{2} \mathrm{~S}_{2 \mathrm{t}},
\end{aligned}
$$

where $S_{i t}$ takes value 1 when $S_{t}$ is equal to $i$ and 0 otherwise. The choice for the number of regimes and autoregressive parameters is based upon a series of tests presented in Section IV. Equation 1 can therefore be written as:

$$
\begin{aligned}
& \mathrm{y}_{\mathrm{t}}=\alpha_{0}+\alpha_{1} \mathrm{~S}_{1 \mathrm{t}}+\alpha_{2} \mathrm{~S}_{2 \mathrm{t}}+\mathrm{z}_{\mathrm{t}}, \\
& \mathrm{z}_{\mathrm{t}}=\phi_{1} \mathrm{z}_{\mathrm{t} \& \mathrm{t}}+\phi_{2} \mathrm{z}_{\mathrm{t} \& 2}+\left(\omega_{0}+\omega_{1} \mathrm{~S}_{1 \mathrm{t}}+\omega_{2} \mathrm{~S}_{2 \mathrm{t}}\right) \epsilon_{\mathrm{t}} .
\end{aligned}
$$

If the sequence of states $\left\{\mathrm{S}_{\mathrm{t}}\right\}$ from 0 to $\mathrm{T}$ were known, it would be possible to write the joint conditional log likelihood function of the sequence $\left\{\mathrm{y}_{\mathrm{t}}\right\}$ as:

$$
\begin{aligned}
\log f\left(\mathrm{y}_{\mathrm{T}}, \ldots, \mathrm{y}_{2} \mid \mathrm{S}_{\mathrm{T}}, \mathrm{S}_{\mathrm{T} \& \mathrm{1}, \ldots}, \ldots\right) & =-\frac{\mathrm{T}}{2} \ln 2 \pi-\sum_{\mathrm{t}^{2} 2}^{\mathrm{T}}\left\{\ln \sigma\left(\mathrm{S}_{\mathrm{t}}\right)+\frac{\mathrm{v}_{\mathrm{t}}^{2}}{2 \sigma\left(\mathrm{S}_{\mathrm{t}}\right)^{2}}\right\} \\
\text { where } \mathrm{v}_{\mathrm{t}} & =\mathrm{z}_{\mathrm{t}}-\phi_{1} \mathrm{z}_{\mathrm{t} \& \mathrm{t}}-\phi_{2} \mathrm{z}_{\mathrm{t} \& 2}=\sigma\left(\mathrm{S}_{\mathrm{t}}\right) \epsilon_{\mathrm{t}},
\end{aligned}
$$

with $\sigma\left(S_{t}\right)$ given by equation (3). Since we do not observe $S_{t}$, but only $y_{t}$ from time 0 to $\mathrm{T}$, a way must be found to make an optimal inference about the current state based on the history of the observed values for $y_{t}$. This is the idea of the non-linear filter proposed by Hamilton. In a recursive fashion similar to the Kalman filter, it gives as a by-product the likelihood function of the $y_{t}^{\prime}$ s: 


$$
f\left(y_{T}, \cdots, y_{2}\right)=\prod_{t^{\prime} 2}^{T} f\left(y_{t} \mid y_{t \& 1}, y_{t \& 2}, \cdots, y_{0}\right)
$$

Hamilton (1989) proposes an algorithm to estimate the parameters $\alpha, \omega, \phi$ and $p_{i j}$ given a specified number of states. In the three-state case, for the construction of the probability structure of the first 2 observations, we use the limiting unconditional probabilities for each state to start the algorithm. These are given by (Chiang(1980), p. 154):

$$
\pi_{\mathrm{i}}=\frac{\mathrm{A}_{\mathrm{ii}}}{\sum_{\mathrm{j}^{\prime} 0}^{2} \mathrm{~A}_{\mathrm{ij}}}, \quad \mathrm{i}=0,1,2
$$

where $A_{i j}$ is the $i^{\text {th }}$ cofactor of the matrix $A=I-P$, with I the $3 \times 3$ identity matrix and $P$ as defined in (2) 7 . As a by-product of the algorithm, we also obtain a sequence of joint conditional probabilities $\mathrm{p}\left(\mathrm{S}_{\mathrm{t}}, \mathrm{S}_{\mathrm{t}-1}, \mathrm{~S}_{\mathrm{t}-2} \mid \mathrm{y}_{\mathrm{t}}, \mathrm{y}_{\mathrm{t}-1}, \ldots, \mathrm{y}_{0}\right)$, which are the probabilities that the series is in state $\mathrm{i}, \mathrm{j}, \mathrm{k}(\mathrm{i}, \mathrm{j}, \mathrm{k}=0,1,2)$ at times $\mathrm{t}, \mathrm{t}-1$, and $\mathrm{t}-2$ respectively, conditional upon the information available at time t. By summing these joint probabilities, one can obtain the so-called filter probabilities, which are the probabilities of being in state 0 , 1 , or 2 at time $t$, given the information available at time t. They are given by:

$$
\left.=j \mid y_{t}, y_{t \& 1}, \ldots, y_{0}\right)=\sum_{i^{\prime} 0}^{2} \sum_{k^{\prime} 0}^{2} p\left(S_{t}=j, S_{t \& 1}=i, S_{t \& 2}=k \mid y_{t}, y_{t \& 1}, \ldots, y_{0}\right) \quad j=
$$

The filter probabilities provide information about the regime in which the series is most likely to be at every point in the sample. They are therefore very useful for dating the various switches. One can also compute similar probabilities with information available at time $t+1, t+2$, until $T$. The probabilities using the information up to the end of the sample are called smoothed probabilities (see Hamilton, 1989) and are more accurate since they are based on more information. Since in our case the smoothed probabilities and the filter probabilities are almost identical, we report only the filter probabilities.

\footnotetext{
' To carry out the maximum likelihood estimation of the various models, we used the DFP and GRADX methods in the OPT and CONOPT subroutines of the GQOPT package. The routine OPT was used for the AR and 2-state models, while CONOPT (a routine for optimization under constraints) was used for the three-state model. The covariance matrix of the estimates was obtained through the OPTMOV option, which gives the numerically computed negative inverse of the Hessian of the log-likelihood function evaluated at the optimum.
} 


\section{Empirical Results and Discussion}

Table I presents the estimation results for the quarterly ex-post real interest rate and the inflation rate for both data sets. We discuss primarily the results obtained with the Citibase series, and stress the main differences with those obtained with the Mishkin data set.

\section{A. The Ex-Post Real Interest Rate}

To make the discussion of the results easier, we label the states as high, middle and low with respect to the value of the mean. The parameter $\alpha_{0}$ then denotes the mean for the low state, $\alpha_{0}+\alpha_{1}$ the mean for the middle state, and finally $\alpha_{0}+\alpha_{2}$ the mean for the high state. Correspondingly, $\omega_{0}, \omega_{0}+\omega_{1}$, and $\omega_{0}+\omega_{2}$ denote the standard deviations for the low, middle, and high states. The filter probabilities, shown in Figure 2, indicate the probability of being in the different states at each point of the sample. The probabilities show that the series is in three persistent states over the sample: from 1961 to 1973 , the series is in the middle state with a mean of $1.4 \%$; from 1973 to the middle of 1981 , the mean is negative $(-1.8 \%)$ for the Citibase series, while it is close to zero (-0.38\%) and not significantly different from it (standard error of 0.32 ) for the Mishkin series; finally, from mid-1981 until the end of the sample, the mean of the series for both data sets is close to $5.5 \%$.

The dating of the shift in the middle of 1981 is of importance in light of the alternative explanations offered for the high level of the real interest rate in the $80 \mathrm{~s}$. As mentioned by Walsh (1988), two explanations prevail: the first attributes the rise in the real interest rate to a restrictive monetary policy and identifies the last quarter of 1979 as its starting point, the second to current and expected federal budget deficits, especially since the 1981-1982 recession. The dating provided by the three-regime model points in the direction of the second explanation.

The presence of these shifts in the mean of the ex-post real interest rate, and especially the large one in 1981, is critical for assessing other properties of the stochastic process describing the real interest rate. As shown by Perron (1990), the presence of a regime shift in the mean of a series might make it very difficult to reject the hypothesis of a unit root, using conventional procedures, even if the series is characterized by i.i.d. innovations around this shifting mean. The shifts identified in the series can therefore explain why Walsh (1987) and Rose (1988) could not reject the unit root in the real rate $^{8}$.

\footnotetext{
${ }^{8}$ Similar results are obtained using our data sets. The Dickey-Fuller (1979) t-statistic to test for a unit root are $-1.51(k=3)$ for the quarterly Citibase series (see Perron $(1990)) ;-2.17(k=2)$ for the quarterly Mishkin series and $-1.85(\mathrm{k}=8)$ for the monthly Mishkin series. The procedure followed to select the truncation lag parameter $k$, described in Campbell and Perron (1991), uses a test of significance (10\% two-tailed t-test) on the coefficient of the last lag in the estimated autoregressions. This is performed in a recursive way
} 
Concerning the volatility of the ex-post real interest rate, our results show that the variance is about the same in the low and high states, but is significantly smaller in the middle state. Hence, volatility increases after 1973, irrespective of the level of the real interest rate. The same pattern carries through to the Mishkin data set, but the variance is smaller across regimes. This heteroskedastic behavior of the series contrasts with the results obtained by Bollerslev (1988) over the period 1951:1 1987:2. He shows, using an ARCH methodology, that the ex-post real rate exhibits no significant heteroskedasticity since the stochastic trend in variance present in the nominal interest rate and the inflation rate is common to the two series. It is to be remembered, however, that his model, like all ARCH models, rests on a chosen specification for the conditional mean. His conclusions depend on the autoregressive specification in first differences chosen for the nominal interest rate and the inflation rate. This choice is based on the non-rejection of a unit root in both series. The same argument made for the non-rejection in the ex-post real interest rate can be made for the nominal interest rate and the inflation rate if important changes in mean occur in these series during this period. Also, Lamoureux and Lastrapes (1990) showed recently, based on Monte-Carlo simulations, that GARCH measures of persistence in variance can be affected by not taking into account structural shifts in the unconditional variance. Indeed, in our case, both the mean and the variance of the nominal interest rate and the inflation rate exhibit such structural shifts.

To conclude the analysis of the real interest rate, it is important to note the absence of autocorrelation in the series once the shifts in mean and variance have been taken into account. The parameters $\phi_{1}$ and $\phi_{2}$ are both close to zero with high standard errors in both data sets.

These results are of substantial interest in two respects. First, they show that the ex-post real interest rate is a random process around a mean which exhibits infrequent but important changes. This is in accord with Fama's (1975) characterization of the ex-ante real interest rate as a constant, when viewed within each regime. The i.i.d. process for the real interest rate within regime also supports the presence of the Fisher effect in each regime, but not over the whole sample. Therefore, the movements in the nominal interest rate contain little information about the movement in the real interest rate, an important result for policy purposes. To see this, note that the Fisher effect asserts that the coefficient $\mathrm{b}$ should be 1 in a regression of the form $i_{t}=c+b \pi_{t}^{e}+u_{t}$. Under this hypothesis this is equivalent to the requirement that $r_{t}=i_{t}-\pi_{t}=\mathbf{c}+\left(\pi_{t}^{e}-\pi_{t}\right)+u_{t}=v_{t}$, an uncorrelated process under the assumption of rational expextations. Our results indicate that the real rate is indeed uncorrelated within regime and the Fisher effect can be said to hold if its definition is extended to allow for infrequent changes in the constant $\mathrm{c}$. Second, the results are also of interest in light of the serial correlation present in the nominal interest rate (see

starting with a maximal value $\mathrm{k}=10$ and eliminating lags until the last one is significant. 
Hamilton (1988)) and the inflation rate (to be discussed below) even when changes in regimes are accounted for. This situation is an interesting example of what Granger and Lin (1990) label as a conjugate process. A conjugate process describes two series which individually exhibit a dynamic structure but which add up to white noise. The real interest rate being the difference between the nominal interest rate and the inflation rate, one can characterize the latter two series as being conjugate.

In Section IV, we conduct various sensitivity analyses to test for the robustness of the chosen specification: tests for the number of states, split-sample and monthly estimations, allowance for different autocorrelation structures in the various states, tests for remaining ARCH effects, and direct tests for two structural changes. All tests tend to confirm that the ex-post real interest rate series is better described as a random sequence with three different means and two different variances.

\section{B. The Inflation Rate}

For labeling the states, we keep the convention used for the ex-post real interest rate. Our results (see Table I and Figure 3 ) document that the U.S. inflation rate went from the low state starting in 1961 (with a mean of $2.7 \%$ and a standard deviation of $2.6 \%$ ) to the high state near the beginning of 1973 . The mean in this high state is almost $9 \%$, but more importantly, the standard deviation is $3.4 \%$, almost three times its pre-1973 level. In the early eighties, according to the inferred filter probabilities, the series seems to oscillate between the middle state and the low state, except at the very end of the sample. This uncertainty regarding the prevailing state in the later part of the sample parallels the debate among economists and policy makers during that period, some claiming that inflation had subsided, others that the threat of high inflation was still present. In this regard, note that the mean of the low state is almost identical to the pre-1973 level, but that the variance is much higher.

We mentioned in the introduction that Huizinga and Mishkin (1986) identified two shifts in the ex-ante real rate which coincided with changes in the Federal Reserve's operating procedures in October 1979 and October 1982. Walsh (1988) argued that the shift in October 1982 was in fact due to a shift in the inflation rate process. The filter probabilities indicate that the inflation rate switched from the high state to the intermediate state (with a probability of 0.62 ) precisely in the fourth quarter of 1982, providing some support to Walsh's argument. For the Mishkin inflation series, the values of the means and variances differ from the Citibase series: the means for the low, middle and high states are $2.3 \%, 4.1 \%$, and $7.5 \%$ respectively, while the corresponding standard deviations are $1.5 \%, 0.7 \%$, and $2.1 \%$. The classification of the points in the various states (see figure 3 ) is also different: after being in the low state until 1966, the series goes into the middle state until 1973 , jumps into the high state until 1983 (but with a 0.63 probability of being in the low state in 1982:4) and alternates between the low and middle states until the end of 1986. 
Our results also bring some new evidence in the debate over the relationship between the level and the variability of inflation. Okun (1971) and Friedman (1977) argue that high inflation is costly because it raises inflation variability, generating relative price distortions and wealth redistributions between creditors and debtors, adding risk in long-term contracting, and causing other welfare costs associated with a high variance of inflation. Okun (1971) and a series of ensuing studies ${ }^{9}$ presented some empirical evidence about the positive correlation between the mean and the variance of inflation. However, using an ARCH model, Engle (1983) did not find any significant correlation between the level of inflation in one period and the variance of unanticipated inflation in the next period. Recently, Ball and Cecchetti (1990) attempted a reconciliation of the conflicting evidence by drawing the distinction between short-term and long-term inflation uncertainty (variance of unanticipated changes in inflation). Their main result is that the level of inflation has a stronger effect on inflation uncertainty at long horizons. This is what the earlier studies had measured, while Engle (1983) measured the short-term effect of the level of inflation on inflation uncertainty. Our results in both data sets show unequivocally that the high mean state is also the high variance state. Moreover, since the probability of staying in the high state once it is reached is close to one, it is the long-term effect on the variability of inflation that we measure. In that sense, we confirm the empirical evidence brought forward before Engle (1983). To really compare the results of our model to Engle's results, we need to construct a one-period ahead forecast for the level of inflation. This is done in the next section.

As we argued for the ex-post real interest rate, the presence of regime shifts in the inflation rate might explain why one cannot reject in general the unit root hypothesis for the inflation rate ${ }^{10}$. Finally, it should be stressed that, unlike the ex-post real interest rate, substantive autocorrelation remains even after taking the shifts into account. This last result supports the claim advanced earlier that the nominal interest rate and the inflation rate are conjugate processes in the sense that each has a noise component that is correlated, yet the difference is uncorrelated when structural changes in mean are taken into account.

\footnotetext{
${ }^{9}$ See Logue and Willett (1976), Foster (1978), Fisher (1981), and Taylor (1981) among others.

${ }^{10}$ See Bollerslev (1988) and Gokey (1990). Similar results hold for our data set. Using the procedure described in footnote 8 , we obtain the following t-statistics for the unit root hypothesis (the $10 \%$ critical value being -2.57$)$ : $-2.25(k=5)$ for the quarterly Citibase series; $-1.82(k=2)$ for the quarterly Mishkin series. For the monthly series, a large number of lags is needed to make the residual white noise, yet none of the statistics with $\mathrm{k}$ greater than 2 are significant at the $10 \%$ level.
} 


\section{Ex-Ante Real Interest Rate and Expected Inflation}

The ex-ante real interest rate is of utmost importance, since it is the rate upon which economic agents base their savings, investment, and portfolio decisions. Some authors have in the past constructed ex-ante series for the real interest rate, e.g. Mishkin (1981) and Antoncic (1986). The recent history is of particular interest because of the turbulence experienced in the 70 s on the inflation front, which is alleged to have pushed the ex-ante real interest rate to negative levels, and because of the fiscal and monetary policy changes of the $80 \mathrm{~s}$ which are cited as the sources for its high positive level (see, e.g., Blanchard and Summers (1984)).

Using the parameter estimates of the three-state model shown in Table I for

$$
\begin{aligned}
& \mathrm{E}\left[\mathrm{y}_{\mathrm{t}+1} \mid\left\{\mathrm{y}_{\mathrm{t}}\right\}\right]^{\prime} \quad \alpha_{0} \% \alpha_{1} \sum_{\mathrm{j}=0}^{2} \mathrm{p}_{\mathrm{j} 1} \operatorname{Pr}\left[\mathrm{S}_{\mathrm{t}}, \quad \mathrm{j} \mid\left\{\mathrm{y}_{\mathrm{t}}\right\}\right] \% \alpha_{2} \sum_{\mathrm{j}=0}^{2} \mathrm{p}_{\mathrm{j} 2} \operatorname{Pr}\left[\mathrm{S}_{\mathrm{t}}, \quad \mathrm{j} \mid\left\{\mathrm{y}_{\mathrm{t}}\right\}\right] \\
& \% \phi_{1}\left\{\mathrm{y}_{\mathrm{t}} \& \quad \alpha_{0} \& \alpha_{1} \operatorname{Pr}\left[\mathrm{S}_{\mathrm{t}}, \quad 1 \mid\left[\mathrm{y}_{\mathrm{t}}\right\}\right] \& \alpha_{2} \operatorname{Pr}\left[\mathrm{S}_{\mathrm{t}}, \quad 2 \mid\left[\mathrm{y}_{\mathrm{t}}\right\}\right]\right\} \\
& \% \phi_{2}\left\{\mathrm{y}_{\mathrm{t}-1} \& \alpha_{0} \& \alpha_{1} \operatorname{Pr}\left[\mathrm{S}_{\mathrm{t}-1}, \quad 1 \mid\left\{\mathrm{y}_{\mathrm{t}}\right\}\right] \& \alpha_{2} \operatorname{Pr}\left[\mathrm{S}_{\mathrm{t}-1}, \quad 2 \mid\left\{\mathrm{y}_{\mathrm{t}}\right\}\right]\right\} \text {. }
\end{aligned}
$$

the two ex-post real rate series, one for each data set, and the corresponding inferred probabilities graphed in Figure 2, we construct two series for the ex-ante real rate according to the following formula: where $\left\{\mathrm{y}_{\mathrm{t}}\right\}$ denotes the past and present history of $y_{t}$ The two ex-ante real rate series are shown in Figure 4 along with the corresponding ex-post series. As expected, the ex-post real interest rate is much more volatile than the ex-ante real interest rate.

In our model, the ex-ante real interest rate is seen as a constant subject to occasional jumps caused by important structural events. Both the negativity of the $70 \mathrm{~s}$ and the high positive levels of the 80 s are clearly present in these point forecasts. The results with the Citibase and Mishkin data sets are qualitatively similar, both showing that the ex-ante real interest rate is constant for sustained periods of time but subject to sudden changes in level. The main difference is that the mean in the period 1973-1980 is close to zero for the Mishkin data series while it is definitely negative for the Citibase data series.

The smooth behavior of the ex-ante real interest rate contrasts with the series previously constructed based on linear models. Antoncic (1986) presents estimates of the ex-ante real interest rate for the period 1965-1984. Her results indicate that the real interest rate was not significantly different from zero throughout most of the 1970 s, and that it increased sharply towards the end of 1980 (almost 3\% in November 1980 with a peak of $7.12 \%$ in March 1982). Although her estimates fluctuate much more than ours, the general conclusions are similar and point to factors other than the Federal Reserve policy change to explain the rise in the real interest rate in the beginning of the 1980 s.

Using formula (8), we can also construct one-step ahead inflation forecasts using the parameter estimates of the three-state model and the corresponding filter 
probabilities. The expected inflation series for the two data sets are shown in Figure 5. Given this series for expected inflation, we can test directly if the inflation rate explains the variance of unanticipated inflation in the next period, and compare our results to Engle's (1983). To do so, we estimate the following regression:

$$
\mathrm{fe}_{\mathrm{t}}^{2}=\boldsymbol{\beta}_{0}+\boldsymbol{\beta}_{1} \pi_{\mathrm{t}-1}+\mathrm{e}_{\mathrm{t}}
$$

where fe denotes the forecast error based on the three-state Markov model and $\pi$ the rate of inflation. The hypothesis to test is $\boldsymbol{\beta}_{1}=0$. The values of $\boldsymbol{\beta}$ obtained for the Citibase and Mishkin series are 0.29 and 0.71 respectively with t-values of 1.86 and 2.16. Our evidence for the period 1961-1986 seems therefore contrary to Engle's results, especially with the Mishkin series for which a strong and significant positive relationship is found between the level of inflation and inflation uncertainty.

To further assess our real interest rate and inflation rate models, we compare their within-sample forecasting ability to a simple random walk model and to an AR(4) model in terms of the mean-squared error over the entire sample. For the real interest rate series, the Markov model yields a mean-squared error of 5.58 and 3.36 for the Citibase and Mishkin quarterly series, respectively, while the random walk model gives values of 8.97 and 5.15, and the AR(4) 5.74 and 3.82. For the inflation rate, the corresponding figures for the Markov model are 7.20 and 3.36, compared to 8.73 and 4.12 for the random walk and 6.11 and 3.11 for the AR(4). Therefore, this criterion tends to favor the Markov model over the random walk and the AR(4) models for the real interest rate, but the AR(4) is the winner for the inflation rate.

\section{Sensitivity Analyses}

In this section, we perform various tests to check for possible misspecifications. First, we verify whether the series are best characterized by three states, and not by one, two or four states. We also estimate the various one, two and three-state models at monthly frequencies to check for the robustness of the specification and coefficient values. The second series of tests concerns the autoregressive structure. Since we assumed that the autoregressive parameters $\phi_{1}$ and $\phi_{2}$ were the same in all three states, we allow these coefficients to differ between states. Third, we test for remaining ARCH effects in the residuals from the estimated three-state models for both the expost real rate and the inflation rate. Finally, we present formal statistical procedures permitting to detect the presence of two break points at unknown dates in order to confirm the existence of two structural changes and the dates of their occurrence.

\section{A. Testing for the number of states}

In the context of Markov switching models, the usual tests (likelihood ratio, Wald, and Lagrange multiplier) do not have the standard asymptotic distribution. The 
problem comes from two sources: under the null hypothesis, some parameters are not identified and the scores are identically zero. To clarify these two irregularities, let us take the case where the null hypothesis is a linear model and the alternative hypothesis a two-state homoskedastic Markov switching model. The null hypothesis can be expressed as $\left\{\alpha_{1}=0\right\}$. To see the problem of unidentified parameters under the null, note that if $\left\{\alpha_{1}=0\right\}$, the transition probability parameter $p$ is unidentified since any value between 0 and 1 will leave the likelihood function unchanged. As for the problem of identically zero scores, note that if $\{\mathrm{p}=1\}$, the scores with respect to $\mathrm{p}, \mathrm{q}$ and $\alpha_{1}$ will be identically zero and the asymptotic information matrix will be singular. Hansen (1992) proposes a bound test that addresses these problems, and Garcia (1992) derives analytically the asymptotic null distributions of the likelihood ratio test for some two-state Markov switching models. However, none of the computed critical values apply strictly to the linear models considered as the null hypothesis below, such as an AR(4). For Markov switching models with more than two states, no critical values currently exist.

We must therefore rely on different tests that try to overcome these problems. The first two, the Davies' (1987) bound test and the Gallant's (1977) test, described in the Appendix, start with the idea of giving a range of values to the parameters under the alternative hypothesis, thus avoiding the problems of estimating them, and construct some statistics based on the value of the objective function obtained with these given parameter values. For the Davies test, one obtains an upper bound for the significance level of the likelihood ratio statistic under the null hypothesis consisting of the model with the lower number of states. Gallant's procedure, suggested by Hamilton (1990) but to our knowledge never applied, consists in calculating the estimated values of the dependent variable associated with given values of the unidentified parameters. These constructed variables (or a few principal components) are added to the model with the lower number of states and their significance is judged according to a F-test.

Finally, contrary to the previous approach, one might still decide to estimate the model with the larger number of states and run tests for non-nested models (Davidson and MacKinnon (1981)). We apply the so-called J-test which uses a t-test on $\delta$ in the regression:

$$
\mathrm{y}_{\mathrm{t}}=(1-\delta) \mathrm{f}_{\mathrm{t}}(\boldsymbol{\beta})+\delta \hat{\mathrm{g}}_{\mathrm{t}}+\mathrm{u}_{\mathrm{t}}
$$

where $f_{t}(\boldsymbol{\beta})$ represents, in our case, the forecast of $y_{t}$ based on a model with the lower number of states and $\hat{g}_{t}$ represents the forecast of $y_{t}$ obtained by using the estimated model with the larger number of states.

\section{A1. Test Results for the Ex-post Real Interest Rate}

To assess whether the ex-post real interest rate is best characterized by a three-regime model, we follow a progressive estimation and testing procedure starting 
with a one-state autoregressive specification and building up to a test for the possible presence of four states. In the one-state model, based on an analysis of the estimated residuals for remaining serial correlation, we opt for an AR(4). Over the sample, the series exhibits a relatively high persistence, the sum of the autoregressive coefficients being 871 .

In the next step, we estimate and test a two-state Markov model with statedependent means and variances. The estimation revealed the presence of a number of local optima, a likely indication of misspecification. Although some of the local optima seem to correspond to important economic events such as the change in the Federal Reserve operating procedures between the end of 1979 and 1982 or the rise in inflation in 1973, the global minimum does not have any ready economic interpretation. The transition probabilities are noticeably smaller, and the filter probabilities identify all the extreme points as belonging to state 1 by attributing to that state a very large variance. As documented in Boldin (1989), this feature may result from the presence of a large autoregressive order. Boldin shows that a series generated by a two-state Markov model can be mistaken for an AR(1) process if only one state is allowed. Going one step further, it could also be the case that significant autoregressive terms in a two-state model are due to the fact that a three-state model is correct. In small samples, spurious autoregressive terms can appear, since the algorithm will artificially increase the value of the function by changing states frequently to closely follow the ups and downs in the series. One diagnostic of this problem is to look at the value of the transition probabilities $\mathrm{p}$ and $\mathrm{q}$ which fall in our case to 0.246 and 0.446 . This spurious effect seems to be supported by the fact that in a model with 2 states and 2 lags, the global minimum is now associated with high transition probabilities (persistent states) and the filter probabilities point to a change in the third quarter of 1973 , the series remaining in this highly variable state until the end of the sample.

These results seem to indicate a misspecification of the two-state, four-lag Markov model, but more likely in the direction of a three-state model since all model selection tests favor the two-state model over the AR(4) (see Table II). The quick rule for the Davies test (see Appendix A) leads to a probability close to zero ( . .3\%) for the likelihood ratio test statistic to be greater than 17.53. The Gallant test was calculated by adding to the one-state AR(4) model the fitted value of the dependent variable based on a two-state model with values of the parameters drawn randomly ${ }^{11}$.

\footnotetext{
${ }^{11}$ We generated the means " according to a normal distribution with mean $\mu$ and standard deviation $<\mathrm{T}$, where $\mu$ was drawn from a uniform distribution over a certain interval and $\mathrm{T}$ from a gamma distribution, $<$ being a scaling factor. For example, for the Citibase real interest rate 1 versus 2 states test, we drew $\mu_{0}$ and $\mu_{1}$ uniformly over the interval $(-0.5,1.9)$ and $(1.9,4.3)$ respectively, i.e. between the mean of the series minus or plus one standard deviation for the low mean state and the high mean state. Then " ${ }_{0}$ and ${ }_{1}$ were drawn from two normal distributions, $\left(\mu_{0}, 0.1 \mathrm{~T}_{0}\right)$ and ; $\left(\mu_{1}, 0.1 \mathrm{~T}_{1}\right)$ respectively, where $\mathrm{T}_{0}$ and $\mathrm{T}_{1}$ are Gamma deviates of integer order 2 , scaled by the factors 0.35 and 0.7 respectively. The Ts so generated served also
} 
We repeat the procedure four times and compute each time the corresponding p-value. We then compute the $p$-value of this multiple test by $\alpha=\min _{\mathrm{j}=1, \cdots, 4}(5-j) \mathrm{P}_{\mathrm{j}}$, where $\mathrm{P}_{1}, \cdots, \mathrm{P}_{4}$ are the ordered $\mathrm{p}$-values corresponding to the four tests, based on Hochberg's (1988) inequality related to multiple hypothesis testing. The test strongly rejects the null hypothesis of a fourth order autoregression with a single regime. The J-test was calculated using the parameter estimates from the model corresponding to one of the local minima to construct the variable $\hat{\mathrm{g}}$ in $(10)$. The estimate of the associated coefficient $\delta$ is 0.998 with a standard error of 0.03 , therefore concurring with the rejection of the two other tests.

We also estimated the two-state Markov specification for the Mishkin series at both quarterly and monthly ${ }^{12}$ frequencies, and tested it against the AR(4) specification. The results generally confirm the rejection of the AR(4) linear model ${ }^{13}$.

Given the results obtained with the two-state model with four autoregressive parameters, one might suspect the presence of a third regime. As a step to assert the presence of such a third state, we split the sample into two sub-samples: 1961:11979:4 and 1973:1-1986:3 and run the two-state algorithm for each sub-sample. The results are shown in Table III. For the Citibase series, both sub-samples exhibit two persistent states. In the first, the mean turns negative (-2\%) starting in 1973 until the end of the sub-sample with an associated higher variance. In the second sub-sample, the mean rises from $-1.8 \%$ for the period 1973:1-1979:4 to 5\% from 1980:1 until the end of the sample. Note, however, that the variance is not significantly different in both states. These results are quite close to the previous three-state estimation results for both series. Note that the evidence about the presence of two regimes in both sub-

for the standard deviations in the two states. The probability parameters were drawn uniformly over the $(0,1)$ interval. We limited the autoregressive structure to two lags, the parameters $\mathrm{N}_{1}$ and $\mathrm{N}_{2}$ being drawn uniformly within the stable triangle $(-0.8,0.8)$

${ }^{12}$ The monthly estimates should be viewed as a check for the robustness of the quarterly results in terms of the number of states. A more appropriate monthly model would include a richer autocorrelation structure, but this would increase the number of parameters and the computational burden, which is already high in a three-state Markov model with 14 parameters and 312 observations.

${ }^{13}$ The results for a test of the single-state AR(4) versus a two-state model (also shown in Table II) are not as clear as with the Citibase data set, since not all test statistics reject the hypothesis that the series is characterized by an AR(4) model. Since we do not have any assessment of the performance of the tests we are using, it might be useful to compare the results we obtained to the results we would have obtained had we used the critical values of the likelihood ratio distribution given in Garcia (1992) for a null hypothesis of a random walk against the alternative of a heteroskedastic two-state Markov switching model, even if they do not apply strictly because of the presence of the AR(4) noise structure. The $1 \%$ and $5 \%$ critical values are 17.38 and 14.11 respectively. For the Citibase series, the results would have been the same. For the Mishkin series, the Davies test would have given the same results, but not the J-test for both the monthly and the quarterly series nor the Gallant test for the quarterly series. 
samples might explain the difficulty encountered by Walsh (1987) to reject the random walk hypothesis over the two subperiods 1961:1-1979:3 and 1970:1-1985:3.

Finally, we formally test the two-state, two-lag specification against the threestate, two-lag model. The test results are shown in Table II. For the Citibase series, all three tests reject the 2 -state model against the 3 -state alternative.

For the Mishkin series, the estimation results for the three-state model at monthly frequency are very similar except, of course, for the autoregressive parameters. The corresponding filter probabilities (not reported) locate the jump from a low state to a high state at the beginning of 1981, but there is more uncertainty about the starting point of the low state (more toward the end of 1973) and there are many switches between the low and the middle states until 1981. The test results (see Table II) also strongly support the three-state specification both for the quarterly and the monthly models. ${ }^{14}$

To sum up, the various model selection tests performed on the ex-post real interest rate seem to strongly support the three-state specification. As a final check of our specification, we looked for evidence of a fourth state by applying the three-state algorithm to the 1961:1-1979:4 and 1973:1-1986:3 sub-samples of the Citibase series. These experiments provided no evidence for the presence of a possible fourth state.

\section{A2. Test Results for the Inflation Rate}

For the inflation rate, we limit ourselves to estimating and testing the twostate model against the three-state model, both at quarterly and monthly frequencies. The test results, also shown in Table II, are rather mixed. While the Davies quick rule fails to reject the two-state model at any significance level, both the Gallant test and the J-test strongly favor the three-state model. Given our current ignorance about the size and power of these different tests, we cannot say much more than state the conflicting results.

Considering the results of the tests, let us comment briefly on the two-state estimation results. According to the estimates of the filter probabilities, both the Citibase and the Mishkin series exhibit a switch to a high mean-high variance state in the third quarter of 1973 which persists until the end of the sample. Given this structure, we find the results of the three-state model richer and more appealing from an economic point of view even if the test results are not all conclusive. The monthly estimates with the Mishkin data set give a higher mean to the high state, but show the same pattern for the variances as the quarterly estimates.

\footnotetext{
${ }^{14}$ Since the single-state AR(4) was not always rejected against the two-state model for this data set, we also calculated statistics to test the single-state AR(4) null hypothesis against a three-state two-lag Markov alternative. The results strongly reject the AR(4) specification.
} 


\section{B. Different Autoregressive Structures in Different Regimes for the Real Interest Rate}

In our three-state, two-lag model for the real interest rate, we constrained the autoregressive parameters $\phi_{1}$ and $\phi_{2}$ to be identical in all states. In this section we investigate whether this assumption is stringent or not by proceeding in two ways. First, we specify a Markov model where the autoregressive parameters depend on the states. This model (model 1) will have four more parameters than our previous specification, for a total of 18 . Another approach (model 2) consists in adding lagged inflation to the original model with fixed autoregressive parameters, since this variable is correlated with the real rate as shown by Mishkin (1981). Therefore, if the autocorrelation differs between regimes, this variable might be able to capture it. The estimation results for both models are shown in Table IV.

In model 1, the estimates of the autoregressive parameters are not significantly different from zero at conventional levels of confidence for both the Citibase and Mishkin series. Note that the introduction of these state-dependent autoregressive parameters lowers by some $2 \%$ the estimates of the means in the various states, but does not affect much the estimates of the standard deviations or the transition probabilities.

For model 2, the estimates for both the Citibase and the Mishkin series are almost identical to those of the model without lagged inflation, and the coefficient of this latter variable is not significantly different from zero. Based on these results, we feel confident that there does not remain any significant autocorrelation in the ex-post real interest rate once the changes in means and variances have been taken into account. The residuals are not however white noise since there remains some heteroskedasticity due to the different variance allowed for each regime. So, a final check on the model would be to see if there remains some autoregressive conditional heteroskedasticity after this state-dependent heteroskedasticity has been accounted for.

\section{Remaining ARCH effects}

To assess the presence of any remaining ARCH effects in the residuals from the three-state real interest rate model, we run two regressions: first, we project the squared residuals on the filter probabilities to account for the state-dependent heteroskedasticity, then we add to the previous regression a fourth-order autoregressive structure for the squared residuals. A F-statistic is computed for the joint significance of the lagged squared residuals. The results are shown in Table V. The value of the F-statistic is 0.83 for the Citibase series and 1.34 for the Mishkin series. Therefore, in both cases, one cannot reject at conventional levels of confidence the absence of any remaining ARCH effects. We can therefore conclude that the real interest rate can be characterized as a white noise process once the shifts in mean and variances are accounted for. Running the same test for the inflation rate, we can reject the absence of remaining ARCH effects at the 5\% level but not at the $1 \%$ level. 


\section{Direct Tests and Dating of Changes with Two Breaks}

To provide additional evidence about the existence of structural changes (and the dates of their occurrences) in the level of the ex-post real interest rate and inflation rate series, we present formal statistical procedures permitting to detect the presence of two break points at unknown dates. The test considered extends earlier work by Banerjee, Lumsdaine, and Stock (1992) and Andrews (1993) who considered tests for a one-time structural change based on the maximal value of an appropriate Wald test over all possible break points. The OLS regression at the basis of the test is the following:

$$
y_{t}=\mu+\delta_{1} 1\left(t>\lambda_{1} T\right)+\delta_{2} 1\left(t>\lambda_{2} T\right)+e_{t}
$$

where $1\left(t>\lambda_{i} \mathrm{~T}\right)=1$ if $\mathrm{t}>\lambda_{\mathrm{i}} \mathrm{T}$ and 0 otherwise $(\mathrm{i}=1,2)$. We assume that $\left(\lambda_{1}, \lambda_{2}\right) \in \Lambda$, where

$$
\Lambda=\left\{\left(\lambda_{1}, \lambda_{2}\right): 0<\epsilon<\lambda_{1}<1-\epsilon, 0<\epsilon<\lambda_{2}<1-\epsilon \text { and } \lambda_{2}>\lambda_{1}+\epsilon\right\} .
$$

Denote by $\mathrm{F}_{\mathrm{T}}\left(\lambda_{1}, \lambda_{2}\right)$ the Wald test for testing the hypothesis that $\delta_{1}=\delta_{2}=0$ for a given pair $\left(\lambda_{1}, \lambda_{2}\right)$. The test considered is given by:

$$
\frac{\hat{\sigma}_{\mathrm{e}}^{2}}{\mathrm{~S}_{\mathrm{T}}^{2}} \sup \mathrm{F}_{\mathrm{T}}=\frac{\hat{\mathrm{o}}_{\mathrm{e}}^{2}}{\mathrm{~S}_{\mathrm{T}}^{2}} \sup _{\left(\lambda_{1}, \lambda_{2}\right) \in \Lambda} \mathrm{F}_{\mathrm{T}}\left(\lambda_{1}, \lambda_{2}\right)
$$

where $\hat{\sigma}_{\mathrm{e}}^{2}=\mathrm{T}^{-1} \sum_{1}^{\mathrm{T}} \hat{\mathrm{e}}_{\mathrm{t}}^{2}$, and $\mathrm{S}_{\mathrm{T}}^{2}$ is a consistent estimate of the so-called long-run variance of the errors. The estimator $\mathrm{S}_{\mathrm{T}}^{2}$ considered in the application is that of Andrews (1991) which uses the quadratic spectral kernel and an automatic procedure to select the bandwidth. We considered two versions of this automatic procedure. One is based on an AR(1) approximation for the residuals $\left\{\hat{e}_{t}\right\}$, and the resulting statistic is denoted Sup $F(1)$. The other is based on an $\operatorname{ARMA}(1,1)$ approximation and the resulting statistic is denoted Sup F(2). Details can be found in Andrews (1991). In both cases, the tests are constructed using the OLS residuals $\left\{\hat{e}_{t}\right\}$ evaluated at the pair $\left(\lambda_{1}, \lambda_{2}\right)$ that maximizes the Wald test. The truncation $\epsilon$ in (12) is set to 0.05 . The limiting distribution of the test and the construction of the associated critical values are discussed in the Appendix.

The results of the test are shown in the top panel of Table VI. Consider first the case of the ex-post real interest rate. For the quarterly series, the results are the same for the Citibase or Mishkin series. For both versions of the Sup F test, the pvalue for the null hypothesis of no structural breaks is less than $1 \%$, indicating a strong rejection. The date of the first change in mean is $72: 3$ and the date of the second change is $80: 1$. The results for the monthly series are similar with the first break 
located at 72:11 and the second at 80:9. The rejections of the null hypothesis of no structural change and the implied dates for the breaks lend strong support for the results obtained above using the Markov-switching methodology.

For the inflation rate series, the tests show a rejection of the null hypothesis of no structural change at the $1 \%$ significance level or lower except for the Citibase quarterly series using the $\operatorname{ARMA}(1,1)$ approximation to construct the automatic bandwidth. The dates of the first break are, somewhat strikingly, exactly the same as those for the ex-post real interest rate. The dates of the second break tend, however, to occur rather later, the estimates ranging from 80:4 for the Citibase quarterly series to 81:9 for the monthly Mishkin series. Though the rejections are less striking than for the ex-post real interest rate, the results again corroborate strongly those obtained with the Markov switching methodology. For all series, either method suggest convincingly the presence of three states occurring each once in the sample.

\section{Conclusion}

The presence of a random walk component in the real interest rate is an important issue, both for public policy concerns and for its theoretical implications. If the real interest rate does not follow a random walk, then shocks to it are temporary in nature and there is a tendency for the real interest rate to revert to some average value. What we have shown in this paper is that this average value is subject to occasional jumps caused by important structural events. One such jump is concomitant with the sudden rise in the oil price in 1973. The dating of the second jump in the middle of 1981 is more in line with a federal budget deficit explanation than with the change of monetary policy that occurred in the end of 1979. Whatever their causes may be, these important jumps in the real interest rate series could well explain the systematic non-rejection of the random walk hypothesis in the recent tests performed by Walsh (1987), Bollerslev (1988), and Rose (1988).

The theoretical implications of the presence of either a unit root or a jump in the real interest rate series are important. Rose (1988) explored the implications of a unit root in the ex-ante real interest rate on the consumption capital asset pricing model (CCAPM). The CCAPM implies that the time series properties of the growth rate of consumption and the real interest rate should be similar. Since for the U.S. data this is not verified, he questions the validity of the CCAPM. The presence of jumps in the real interest rate series is also very important for financial theoretical models, as demonstrated by Ahn and Thompson (1988). In particular, they find that jump diffusion processes in the underlying state variables tend to invalidate standard capital asset pricing models. The evidence we presented for the constancy of the ex-ante real interest rate over reasonably lengthy periods of time should also be of some comfort 
to financial theorists, who are often forced for the sake of model tractability to assume that it is constant. 
References

Ahn, C.M. and H.E. Thompson (1988), "Jump-Diffusion Processes and the Term Structure of Interest Rates", Journal of Finance, 43, 155-174.

Andrews, D.W.K (1991), "Heteroskedasticity and Autocorrelation Consistent Covariance Matrix Estimation", Econometrica, 59, 817-858.

Andrews, D.W.K (1993), “Tests for Parameter Instability and Structural Change with Unknown Change Point", Econometrica, 61, 821-856.

Antoncic, M. (1986), "High and Volatile Real Interest Rates: Where Does the Fed Fit in?", Journal of Money, Credit and Banking, 18, 18-27.

Ball, L. and S.G. Cecchetti (1990), "Inflation and Uncertainty at Short and Long Horizons", Brookings Papers on Economic Activity, No. 1, 215-254.

Banerjee, A., R.L. Lumsdaine and J.H. Stock (1992), "Recursive and Sequential Tests of the Unit Root and Trend-Break Hypotheses: Theory and International Evidence", Journal of Business and Economic Statistics, 10, 271-287.

Blanchard, O.J. and L.H. Summers (1984), "Perspectives on High World Real Interest Rates", Brookings Papers on Economic Activity, No. 2, 273-324.

Boldin, M.D. (1989), "Characterizing Business Cycles with a Markov Switching Model", mimeo, University of Pennsylvania.

Bollerslev, T. (1988), "Integrated ARCH and Cointegration in Variance", mimeo, Northwestern University.

Bonomo, M. and R. Garcia (1991), "Consumption and Equilibrium Asset Pricing: An Empirical Assessment”, CRDE working paper no. 2991, Université de Montréal.

Campbell, J.Y. and P. Perron (1991), "Pitfalls and Opportunities: What Macroeconomists Should Know about Unit Roots", NBER Macreconomics Annual, O.J. Blanchard and S. Fisher (eds), 141-201.

Chiang, C.L. (1980), An Introduction to Stochastic Processes and Their Applications, New York, Krieger Publishing Co.

Davidson, R. and J.G. MacKinnon (1981), "Several Tests for Model Specification in the Presence of Alternative Hypotheses", Econometrica, 49, 781-793.

Davies, R.B. (1987), "Hypothesis Testing when a Nuisance Parameter is Present Only Under the Alternative", Biometrika, 74, 33-43.

Dickey, D.A. and W.A. Fuller (1979), "Distribution of the Estimators for Autoregressive Time Series with a Unit Root", Journal of the American Statistical Association, 74, 427-431. 
Engle, R.F. (1983), "Estimates of the Variance of U.S. Inflation Based upon the ARCH Model", Journal of Money, Credit and Banking, 15, 286-301.

Fama, E.F. (1975), "Short-term Interest Rates as Predictors of Inflation", American Economic Review, 65 , 269-282.

Fama, E.F. and M.R. Gibbons (1982), "Inflation, Real Returns, and Capital Investment", Journal of Monetary Economics, 9, 297-323.

Fisher, S. (1981), "Towards an Understanding of the Costs of Inflation: II", CarnegieRochester Conference Series on Public Policy, 15, 5-42.

Foster, E. (1978), "The Variability of Inflation", Review of Economics and Statistics, $60,346-50$.

Friedman, M. (1977), "Nobel Lecture: Inflation and Unemployment", Journal of Political Economy, 85, 451-472.

Gallant, A.R. (1977), "Testing for a Nonlinear Regression Specification: A Nonregular Case", Journal of the American Statistical Association, 72, 523-530.

Garbade, K. and P. Wachtel (1978), "Time Variation in the Relationship Between Inflation and Interest Rates", Journal of Monetary Economics, 4, 755-765.

Garcia, R. (1992), "Asymptotic Null Distribution of the Likelihood Ratio Test in Markov Switching Models”, mimeo, Université de Montréal, May 1992.

Gokey, T.C. (1990), "Stationarity of Nominal Interest Rates, Inflation, and Real Interest Rates", mimeo, Oxford University.

Goldfeld, S.M. and R.E. Quandt, (1973), "A Markov Model for Switching Regressions", Journal of Econometrics, 1, 3-16.

Granger, C.W.J. and J.-L. Lin (1990), "Conjugate Processes", mimeo, University of California at San Diego.

Hamilton, J.D. (1988), "Rational Expectations Econometric Analysis of Changes in Regimes: An Investigation of the Term Structure of Interest Rates", Journal of Economic Dynamics and Control, 12, 385-423.

Hamilton, J.D. (1989), "A New Approach to the Economic Analysis of Nonstationary Time Series and the Business Cycle", Econometrica, 57, 357-384.

Hamilton, J.D. (1990), "Analysis of Time Series Subject to Changes in Regime", Journal of Econometrics, 45, 39-70.

Hansen, B.E. (1992), “The Likelihood Ratio Test under Non-standard Conditions: Testing the Markov Switching Model of GNP", Journal of Applied Econometrics, $7,561-582$.

Huizinga, J. and F.S. Mishkin (1984), "Inflation and Real Interest Rates on Assets with Different Risk Characteristics", Journal of Finance, 34, 699-714. 
Huizinga, J. and F.S. Mishkin (1986), "Monetary Policy Regime Shifts and the Unusual Behavior of the Real Interest Rates", Carnegie-Rochester Conference on Public Policy, 24, 231-274.

Lamoureux, C. and W. Lastrapes (1990), "Persistence in Variance, Structural Change, and the GARCH Model", Journal of Business \& Economic Statistics, 8, 225234.

Logue, D.E. and Willett, T.D. (1976), "A Note on the Relation between the Rate and Variability of Inflation", Economica, 43, 151-58.

Mishkin, F.S. (1981), "The Real Interest Rate: An Empirical Investigation", Carnegie-Rochester Conference Series on Public Policy, 15, 151-200.

Mishkin, F.S. (1990), "What Does the Term Structure Tell us About Future Inflation?", Journal of Monetary Economics, 25, 77-95.

Nelson, C.R. and G.W. Schwert (1977), "Short-term Interest Rates as Predictors of Inflation: On Testing the Hypothesis that the Real Rate of Interest is Constant", American Economic Review, 67, 478-486.

Okun, A.M. (1971), "The Mirage of Steady Inflation", Brookings Papers on Economic Activity, No. 2, 486-98.

Perron, P. (1990), "Testing for a Unit Root in a Time Series with a Changing Mean", Journal of Business \& Economic Statistics, 8, 153-162.

Rose, A.K. (1988), "Is the Real Interest Rate Stable?", Journal of Finance, 43, 1095-1112.

Shiller, R.J. (1980), "Can the Fed Control Real Interest Rates?", in Rational Expectations and Economic Policy, S. Fisher (ed), University of Chicago Press, 117-156.

Taylor, J. B. (1981), "On the Relation between the Variability of Inflation and the Average Inflation Rate", Carnegie-Rochester Conference Series on Public Policy, $15,57-86$.

Walsh, C.E. (1987), "Three Questions Concerning Nominal and Real Interest Rates", Economic Review, Federal Reserve Bank of San Francisco, No. 4, 5-20.

Walsh, C.E. (1988), "Testing for Real Effects of Monetary Policy Regime Shifts", Journal of Money, Credit and Banking, 393-401. 


\section{Appendix}

\section{Davies' (1987) Bound Test}

The procedure proposed by Davies applies when a vector $y$ of dimension q, contained in some parameter space $\Omega$, is present only under the alternative hypothesis. Define the likekihood ratio statistic as a function of $y$ :

$$
\operatorname{LR}(\mathrm{Y})=2\left(\ln \mathrm{L}_{1}\left(\mathrm{Y}_{\mathrm{g}}\right)-\ln \mathrm{L}_{0}^{*}\right)
$$

where $L_{1}\left(V_{g}\right)$ denotes the likekihood value of the objective function evaluated at $Y_{a}$ (a given value for $Y$ ) under the alternative hypothesis, and $L_{0}{ }^{*}$ the maximized value obtained under the null hypothesis (where $y$ is not present). Let $Y^{*}$ be the argmax of $L_{1}(Y)$ and denote the likelihood function under the alternative evaluated at $y^{*}$ by $L_{1}{ }^{*}$. Then $\sup _{y \in \Omega} L R(y) \equiv 2\left(\ln L_{1}{ }^{*}-\ln L_{0}{ }^{*}\right)$. Denote by $M$ the empirically observed value of $2\left(\ln L_{1}{ }^{*}-\ln L_{0}{ }^{*}\right)$. Davies derives the following upper bound for the significance of $M$ :

$$
\underset{\mathrm{P} \in \Omega}{\operatorname{Pr}[\sup } \operatorname{LR}(\mathrm{Y})>\mathrm{M}] \leq \operatorname{Pr}\left[\mathrm{X}_{\mathrm{q}}^{2}>\mathrm{M}\right]+\mathrm{VM}^{\frac{\mathrm{q}-1}{2}} \exp ^{-\frac{\mathrm{M}}{2}} \frac{2^{\frac{-\mathrm{q}}{2}}}{\Gamma\left(\frac{\mathrm{q}}{2}\right)}
$$

where $\Gamma($.$) denotes the gamma function and V$ is defined as:

$$
\begin{aligned}
V & =\int_{Y^{\prime \prime} Y}^{Y^{\prime \prime}}\left|\frac{\partial \operatorname{LR}(Y)^{\frac{1}{2}}}{\partial Y}\right| d y \\
& =\left|\operatorname{LR}\left(Y_{1}\right)^{\frac{1}{2}}-\operatorname{LR}\left(Y_{\mathrm{a}}\right)^{\frac{1}{2}}\right|+\left|\operatorname{LR}\left(Y_{2}\right)^{\frac{1}{2}}-\operatorname{LR}\left(Y_{1}\right)^{\frac{1}{2}}\right|+\cdots+\left|\operatorname{LR}\left(Y_{\mathrm{u}}\right)^{\frac{1}{2}}-\operatorname{LR}\left(Y_{n}\right)^{\frac{1}{2}}\right|,
\end{aligned}
$$

where $Y_{1}, Y_{2}, \ldots, Y_{n}$ are the turning points of $L R(Y)$. A quick rule is obtained upon making the assumption that the likelihood ratio has a single peak. In 
that case $V$ reduces to $2 \mathrm{M}^{1 / 2}$. Our testing procedure uses this quick rule and estimates the model under the alternative hypothesis to obtain $L_{1}{ }^{*}$ (and therefore $\mathrm{M}$ and $\mathrm{V}$ ) to calculate the significance level.

\section{Gallant's Test Procedure}

Consider the following models under the null and alternative hypotheses:

$$
\begin{aligned}
& H_{0}: y_{t}=g\left(x_{t}, \psi\right)+e_{t}, \\
& H_{1}: y_{t}=g\left(x_{t}, \psi\right)+T d\left(x_{t}, \varphi\right)+e_{t} .
\end{aligned}
$$

Let $z_{t}$ be a given vector of variables which do not depend on unknown parameters. If $\mathrm{T}_{0}$, the true value of $\mathrm{T}$, is equal to 0 , the least squares estimator of $\delta$ in the following regression:

$$
y_{t}=g\left(x_{t}, \psi\right)+z_{t}^{\prime} \delta+e_{t}
$$

is estimating the null vector. Let $\beta \equiv\left(\alpha_{0}, \alpha_{1}, \alpha_{2}, \omega_{0}, \omega_{1}, \omega_{2}, p_{i, j}(i, j=0,1,2)\right)$ be the vector of parameters in the three-state model (in the two-state model the vector is defined similarly without $\alpha_{2}, \omega_{2}$, and $\left.p(i, j=2)\right)$. The Gallant procedure applied to determining the number of states in a Markov switching model follows four steps:

i) For a given set of values for $\beta$ (say $m$ ) indexed by $i$, calculate the fitted values $\hat{y}_{i}$ for the model with the larger number of states.

ii) If the matrix $Y \equiv\left(y_{1}, \ldots, y_{m}\right)$ is too big, extract a few principal components, say $\mathrm{d}$, (or the first few vectors of the orthogonal matrix in a singular value decomposition of $Y$ ).

iii) Add these principal components (call them $z_{t}$, a vector of dimension $d$ ) to the model with the lower number of states, i.e. estimate (A.3) where the function $g\left(x_{t}, \psi\right)$ represents the model with the lower number of states. 
iv) Compute the following residual sums of squares:

$$
\begin{aligned}
& \mathrm{H}_{1}: \quad \tilde{\sigma}^{2}=\sum_{\mathrm{t}=1}^{\mathrm{T}}\left(\mathrm{y}_{\mathrm{t}}-\mathrm{g}\left(\mathrm{x}_{\mathrm{t}}, \tilde{\varphi}\right)-\tilde{\delta} z_{\mathrm{t}}\right)^{2}, \\
& \mathrm{H}_{0}: \quad \hat{\sigma}^{2}=\sum_{\mathrm{t}=1}^{T}\left(y_{\mathrm{t}}-g\left(x_{\mathrm{t}}, \hat{\varphi}\right)\right)^{2} .
\end{aligned}
$$

The likelihood ratio test, with size $\alpha$, rejects the null hypothesis if:

$$
\frac{\hat{\sigma}^{2}}{\tilde{\sigma}^{2}}>1+\frac{d F_{\alpha}}{(T-d-\mu)}
$$

where $\mu$ is the number of parameters estimated under the null hypothesis, $d$ is the dimension of the vector $z_{t}$ and $F_{\alpha}$ denotes the $\alpha$ percentage point of a $F(d, T-\mu-d)$ distributed random variable.

\section{The Limiting Distribution of the Sup F Test with Two Breaks}

We describe in more detail the two-break Sup-F test applied in Section IV.D. Let $R=\left(r_{1}, r_{2}\right)^{\prime}, r_{1}=(0,1,0), r_{2}=(0,0,1) ; \hat{\theta}=\left(\hat{\mu}, \hat{\delta}_{1}, \hat{\delta}_{2}\right)$, the vector of OLS efmestomiegesion $(11), X=\left(X_{1}, X_{2}, X_{3}\right)$ with $X_{i}=\left(X_{i 1}, \cdots, X_{i T}\right)^{\prime}, X_{1 t}=1, X_{2 t}=1\left(t>\lambda_{1} T\right)$ and $\quad x_{3 t}=1\left(t>\lambda_{2} T\right)$. Also $\hat{\sigma}_{e}^{2}=T^{-1} \sum_{1}^{T} \hat{e}_{t}^{2}$. We then have: $F_{T}\left(\lambda_{1}, \lambda_{2}\right)=(R \hat{\theta})\left[R\left(X^{\prime} X\right)^{-1} R^{\prime}\right]^{-1} R \hat{\theta} / \hat{\sigma}_{e}^{2}$. The test considered is given by: $\sup F_{T} \equiv \sup _{\left(\lambda_{1}, \lambda_{2}\right) \in \Lambda} F_{T}\left(\lambda_{1}, \lambda_{2}\right)$. We derive the limiting distribution of sup $F_{T}$ under the null hypothesis of no structural change allowing substantial heterogeneity and correlation in the data. More precisely, under $\mathrm{H}_{0}$, we suppose that: $y_{t}=\mu+v_{t}$, where $v_{t}$ satisfies the conditions for the application of a functional central limit theorem, namely 
$T^{-1 / 2} \sum_{t=1}^{[T r]} V_{t} \Rightarrow \sigma W(r)$ where $W(r)$ is the unit Wiener process defined on $C[0,1]$ and $\quad \sigma^{2}=\lim _{\mathrm{T} 64} T^{-1} E\left(S_{T}^{2}\right)$, with $\quad S_{T}=\sum_{j=1}^{T} V_{j}$. We also assume $\sigma_{v}^{2}=\lim _{T 64} T^{-1} \sum_{1}^{T} E\left(v_{t}^{2}\right)$. Under these conditions we have:

$$
\operatorname{Sup} F_{T} \Rightarrow \frac{\sigma^{2}}{\sigma_{v}^{2}} \operatorname{SupF} \equiv \frac{\sigma^{2}}{\sigma_{v}^{2}} \operatorname{Sup}_{\left(\lambda_{1}, \lambda_{2}\right) \in \Lambda} F\left(\lambda_{1}, \lambda_{2}\right)
$$

where: $F\left(\lambda_{1}, \lambda_{2}\right)=\frac{\left[\lambda_{2} W(1)-W\left(\lambda_{2}\right)\right]^{2}}{\left(1-\lambda_{2}\right) \lambda_{2}}+\frac{\left[\lambda_{2} W\left(\lambda_{1}\right)-\lambda_{1} W\left(\lambda_{2}\right)\right]^{2}}{\lambda_{1} \lambda_{2}\left(\lambda_{2}-\lambda_{1}\right)}$. The proof of (A.4)

follows standard arguments and is omitted. To provide a statistic that is asymptotically free of nuisance parameters, we consider the following rescaled version:

$$
\frac{\hat{\mathrm{o}}_{\mathrm{e}}^{2}}{\mathrm{~S}_{\mathrm{T}}^{2}} \operatorname{Sup} \mathrm{F}_{\mathrm{T}} \Rightarrow \operatorname{Sup}_{\left(\lambda_{1}, \lambda_{2}\right) \in \Lambda} \mathrm{F}\left(\lambda_{1}, \lambda_{2}\right)
$$

where $\hat{\sigma}_{e}^{2}=\mathrm{T}^{-1} \sum_{1}^{\mathrm{T}} \hat{\mathrm{e}}_{\mathrm{t}}^{2}$ is a consistent estimate of $\sigma_{v}^{2}$ under the null hypothesis, and $\mathrm{S}_{\mathrm{T}}^{2}$ is a consistent estimate of $\sigma^{2}$.

To obtain asymptotic critical values, we simulate directly the asymptotic distribution expressed in (A.5). To that effect, we approximate the Wiener process $W(r)$ by the partial sums $N^{-1 / 2} \sum_{i=1}^{[N r]} u_{j}$ with $u_{j} \sim$ i.i.d. $N(0,1)$. We use $\mathrm{N}=1,000$ steps. The number of replications is 10,000 . The critical values obtained are presented in the bottom panel of Table $\mathrm{VI}$. 